\title{
OPDA Has Key Role in Regulating Plant Susceptibility to the Root-Knot Nematode Meloidogyne hapla in Arabidopsis
}

\author{
Cynthia Gleason ${ }^{1,2 *}$, Natthanon Leelarasamee ${ }^{1}$, Dorothea Meldau ${ }^{3}$ and Ivo Feussner ${ }^{3,4}$ \\ ${ }^{1}$ Department of Plant Molecular Biology and Physiology, Georg August University - Albrecht von Haller Institute, Göttingen, \\ Germany, ${ }^{2}$ Department of Plant Molecular Biology and Physiology, Georg August University - Göttingen Center for \\ Molecular Biosciences, Göttingen, Germany, ${ }^{3}$ Department of Plant Biochemistry, Georg August University - Albrecht von \\ Haller Institute, Göttingen, Germany, ${ }^{4}$ Department of Plant Biochemistry, Georg August University - Göttingen Center for \\ Molecular Biosciences, Göttingen, Germany
}

\section{OPEN ACCESS}

Edited by: Xin Li,

University of British Columbia

Canada

Reviewed by:

Zhilong Bao,

University of Florida, USA

Fabien Baldacci-Cresp,

Université Libre de Bruxelles, Belgium

*Correspondence:

Cynthia Gleason

cynthia.gleason@wsu.edu

${ }^{+}$Present address:

Cynthia Gleason

Department of Plant Pathology, Washington State University, Pullman,

WA, USA

Specialty section:

This article was submitted to

Plant Biotic Interactions,

a section of the journal

Frontiers in Plant Science

Received: 10 August 2016 Accepted: 05 October 2016 Published: 24 October 2016

Citation:

Gleason C, Leelarasamee N, Meldau D and Feussner I (2016) OPDA Has Key Role in Regulating Plant Susceptibility to the Root-Knot Nematode Meloidogyne hapla in Arabidopsis.

Front. Plant Sci. 7:1565. doi: 10.3389/fpls.2016.01565
Jasmonic acid $(\mathrm{JA})$ is a plant hormone that plays important roles in regulating plant defenses against necrotrophic pathogens and herbivorous insects, but the role of JA in mediating the plant responses to root-knot nematodes has been unclear. Here we show that an application of either methyl jasmonate (MeJA) or the JA-mimic coronatine (COR) on Arabidopsis significantly reduced the number of galls caused by the rootknot nematode Meloidogyne hapla. Interestingly, the MeJA-induced resistance was independent of the JA-receptor COI1 (CORONATINE INSENSITIVE 1). The MeJAtreated plants accumulated the JA precursor cis-(+)-12-oxo-phytodienoic acid (OPDA) in addition to JA/JA-Isoleucine, indicating a positive feedback loop in JA biosynthesis. Using mutants in the JA-biosynthetic pathway, we found that plants deficient in the biosynthesis of JA and OPDA were hyper-susceptible to M. hapla. However, the opr3 mutant, which cannot convert OPDA to JA, exhibited wild-type levels of nematode galling. In addition, mutants in the JA-biosynthesis and perception which lie downstream of opr3 also displayed wild-type levels of galling. The data put OPR3 (OPDA reductase 3) as the branch point between hyper-susceptibility and wild-type like levels of disease. Overall, the data suggests that the JA precursor, OPDA, plays a role in regulating plant defense against nematodes.

Keywords: COl1, induced resistance, Jasmonic acid, nematodes, opda, plant defense, plant hormones

\section{INTRODUCTION}

Root-knot nematodes (Meloidogyne sp.) are small soil-borne pathogens that can infect more than 5,000 different plant species and cause significant yield losses (Sasser and Freckman, 1987; Koenning et al., 1999; Trudgill and Blok, 2001). During plant infection, stage 2 juveniles (J2) penetrate the roots behind the root cap and migrate intercellularly into the root vasculature where they will eventually settle and form feeding sites. During feeding site formation, the nematode chooses between 2 and 12 plant cells to pierce with its feeding stylet and induce several rounds of cellular endoreduplication without cytokinesis; the resulting enlarged, multinucleate feedings cells are called giant cells (Williamson and Gleason, 2003; Gheysen and Mitchum, 2011; 
de Almeida Engler and Gheysen, 2013; Perry and Moens, 2013). The giant cells give the nematode the nutrients to provide the energy to complete its life cycle and the adult female will lay eggs in a gelatinous matrix on the outside of the root. While the giant cells are forming, the parenchyma cells that surround the giant cells also divide, and as a result, large root galls, also known as "root knots," develop in the root systems. Root galling is one of the most obvious disease symptoms resulting from root-knot nematode infection, and it can reflect disease severity.

Jasmonic acid (JA) is an important plant hormone with roles in plant development and defense (Browse, 2005; Glazebrook, 2005; Shah, 2009; Wasternack and Hause, 2013; Heitz et al., 2016). JA is derived from polyunsaturated $\alpha$-linolenic acid $(18: 3(n-3) ; x: y(n-z)$ denotes a fatty acid with $x$ carbons and $y$ double bonds in position $z$ counting from the methyl end) and roughanic acid (16:3(n-3)), which are oxygenated by either 9-lipoxygenases (LOX1 and LOX5 in Arabidopsis) or 13lipoxygenases (LOX2, LOX3, LOX4, and LOX6 in Arabidopsis) (Bannenberg et al., 2009). The 13-LOX makes 13-hydroperoxyoctadecatrienoic acid (13-HPOT) from 18:3(n-3) and 11hydroperoxy-hexadecatrienoic acid (13-HPHT) from 16:3( $n$ $3)$. Both are substrates for allene oxide synthase (AOS). The AOS products are converted to cis- $(+)$-12-oxo-phytodienoic acid (OPDA) or dinor-12-oxo-phytodienoic acid (dn-OPDA) by allene oxide cyclase (Stenzel et al., 2003). The cyclopentenones are then transported into the peroxisome where they are converted to cyclopentanones by the peroxisomal enzyme OPR3 (OPDA reductase 3). The CoA esters of the products of OPR3 are subjected to $\beta$-oxidation by acyl-CoA oxidase (ACX) enzymes, leading to JA (Stintzi and Browse, 2000). JA moves to the plant cytoplasm where it can be converted to many compounds, including (+)-7-iso-jasmonoyl-L-isoleucine (JA-Ile), which can bind to the JA-receptor COI1 in Arabidopsis (Fonseca et al., 2009) (Figure 1). The binding of JA-Ile to COI1 ultimately releases transcriptional repression of JA-responsive genes (Chini et al., 2007; Thines et al., 2007; Yan et al., 2007). Transcriptional profiling has shown that a majority of JAresponsive genes are COI1-dependent (Devoto et al., 2005; Taki et al., 2005).

Pathogens have evolved sophisticated strategies in order to avoid plant defenses. For example, the bacterium Pseudomonas syringae produces a toxin called coronatine (COR) (Feys et al., 1994). COR is a structural mimic of JA-Ile and it can interact with COI1 with even higher affinity than JA-Ile (Bender et al., 1999; Yan et al., 2009). P. syringae induces salicylic acid (SA)mediated defense, but COR promotes bacterial virulence by taking advantage of the negative cross-talk between JA and SA. By mimicking JA, COR helps to abrogate the SA-mediated defenses against this bacterial pathogen. In addition, COR prevents stomatal closure which facilitates the invasion of $P$. syringae into the plant through these openings (Brooks et al., 2005; Cui et al., 2005; Melotto et al., 2006).

For plant-parasitic nematodes, there is no evidence that the nematode is making a JA-mimic like COR to facilitate infection. However, during the early stages of giant cell formation in Arabidopsis, defense gene expression is downregulated relative to the expression in the un-infected tissue

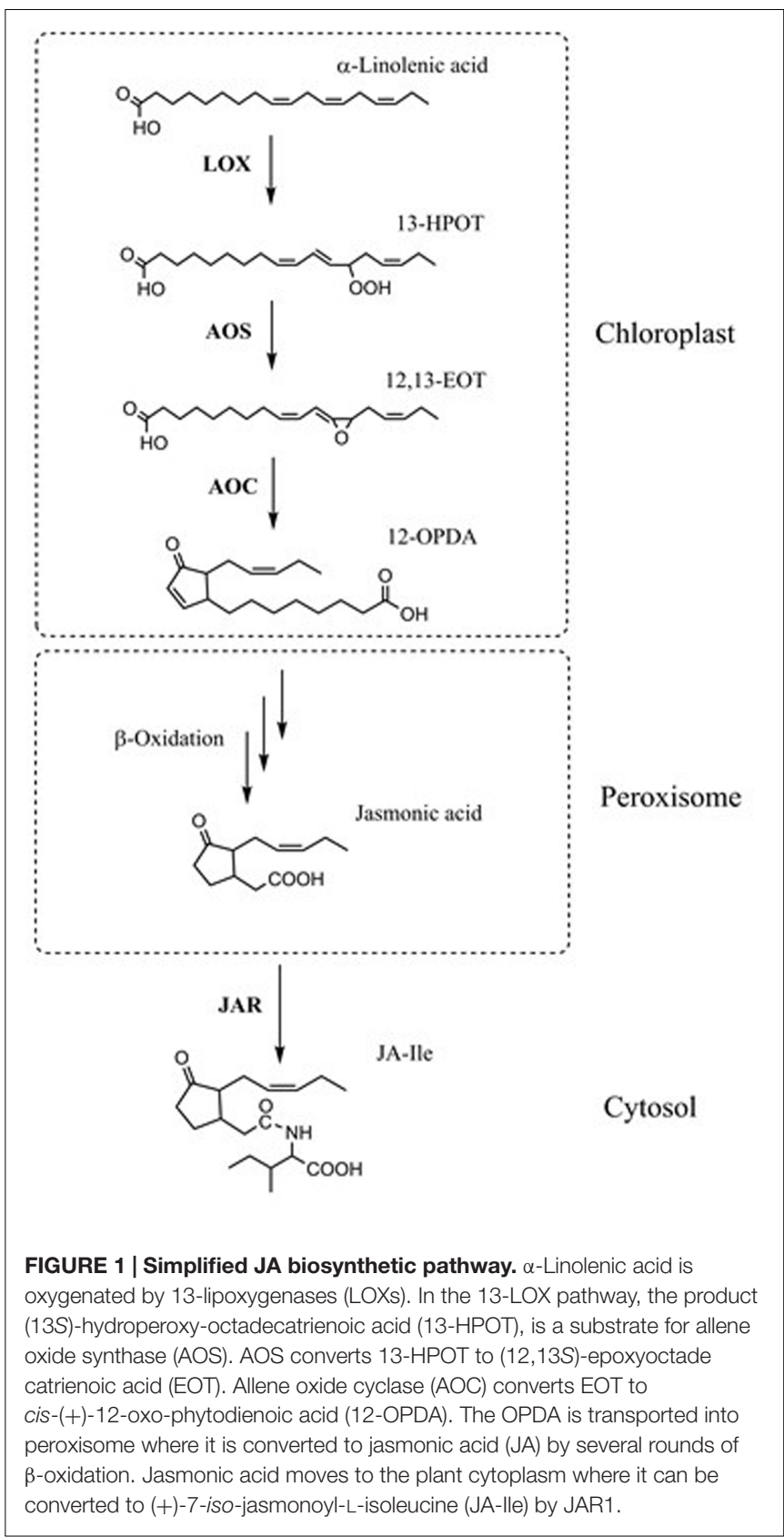

(Barcala et al., 2010). In Medicago truncatula giant cells, genes involved in the biosynthesis of JA and its derivatives are downregulated (Damiani et al., 2012). Some JA-biosynthesis genes and JA-signaling responses are down-regulated during cyst nematode Heterodera glycines infection of susceptible soybean (Ithal et al., 2007a,b). During the early compatible interaction with rice, Meloidogyne graminicola suppresses defense gene expression, including the JA-responsive PR gene JiOsPR10 (Nahar et al., 2011). These data would suggest that, in general, plant parasitic nematodes are actively downregulating defense gene expression, and in particular, suppressing the JA-mediated signaling pathways. Conversely, exogenous applications of MeJA and JA have been shown to activate nematode resistance in 
several crop plants (Soriano et al., 2004a,b; Cooper et al., 2005). In rice the MeJA-induced resistance correlated with enhanced expression of JA biosynthesis and defense genes (Nahar et al., 2011). It seems that upon MeJA-treatment, the nematode is no longer efficiently able to suppress or counteract plant defenses.

Although the data above would suggest that JA is involved in plant defense against nematodes, the role of JA is confounded by several reports suggesting that JA is required for nematode susceptibility. For example, Bhattarai et al. (2008) found that the JA perception mutant in tomato, jail, had significantly reduced M. incognita infection. JAI1 in tomato is homologous to COI1 in Arabidopsis. Furthermore, work in maize has studied ZmLOX3 and found that it mediates suppression of biosynthesis of JA and SA (Gao et al., 2008). Therefore, Zmlox3-4, had increased levels of JA and SA, and yet the plants were more susceptible to root-knot nematodes compared to the wild type (Gao et al., 2008).

In this paper we show that by adding exogenous MeJA or the JA-mimic COR, we could induce resistance to the Northern root-knot nematode Meloidogyne hapla in Arabidopsis. We then utilized well-characterized JA signaling and biosynthesis mutants from Arabidopsis and found that COI1 is not required for nematode susceptibility and the MeJA-induced resistance is COI1-independent. Most importantly, our data provides evidence that the JA-precursor OPDA, not JA/JA-Ile, is a key defense signaling molecule involved in regulating plant susceptibility to nematodes.

\section{MATERIALS AND METHODS}

\section{Plant Genotypes}

Seeds of Arabidopsis (Arabidopsis thaliana) accession Columbia (Col-0) (N1093) were used as wild-type controls when working with mutants in the Col-0 background. Mutants were dde22 (von Malek et al., 2002), coil-t (SALK 035548) from I. Heilmann (Martin-Luther University); acx1/5 (Schilmiller et al., 2007), fad3-2 fad7-2 fad8 (McConn and Browse, 1996), tir1 (Salk CS3798) (Ruegger et al., 1998) and cyp20-3 (SALK_001615C) (Dominguez-Solis et al., 2008). The Wassilewskija (WS) ecotype was used as the control with opr3 (Stintzi and Browse, 2000) which is a mutant in the WS background.

\section{Nematode bioassays}

To collect Meloidogyne hapla strain VW9 eggs, roots from infected tomato (Solanum lycopersicum Green Zebra) were mixed vigorously for $4 \mathrm{~min}$ in $10 \%$ commercial bleach for $5 \mathrm{~min}$. The eggs were collected on a $25 \mu \mathrm{m}$ sieve. The eggs were further surface sterilized in $10 \%$ bleach for $5 \mathrm{~min}$ and immediately rinsed one-time in water before another bleach step (10\%, $5 \mathrm{~min})$. The eggs then were washed three times with sterile $\mathrm{H}_{2} \mathrm{O}$ and then re-suspended in $5 \mathrm{ml}$ water with $1 \%$ SDS and 2\% Plant Preservative Mixture (Plant Cell Technology). Freshly hatched J2 were collected as described (Gleason et al., 2008).

Arabidopsis seeds were surface sterilized in 70\% ethanol (EtOH) for $10 \mathrm{~min}$, washed in $95 \% \mathrm{EtOH}$ and allowed to airdry. Seeds were placed MS media with $20 \%$ sucrose and placed in a growth chamber at $22^{\circ} \mathrm{C} / 18^{\circ} \mathrm{C}, 80-100 \mu \mathrm{mol}$ Photons $/ \mathrm{m}^{2} / \mathrm{s}$,
$14 \mathrm{~h}$ light/10 h dark, 60\% humidity. For the pre-treatment assays, plants were transferred to MS with or without $50 \mu \mathrm{M}$ MeJA or $1 \mu \mathrm{M}$ COR (final concentration). After $48 \mathrm{~h}$ in the growth chamber, plants were either collected for gene expression analysis or used in nematode assays. For gene expression analysis, root tissue was collected and frozen in liquid nitrogen. For the pre-treatment infection assays and for the tirl bioassays, five plants were transferred to modified KNOPs media in 100 square centimeter petri dishes and each plant was inoculated with 100 surface sterilized $M$. hapla J2. Inoculated plants were incubated in 14:10 h light: dark growth conditions. Galls were counted at 14 dpi (days post-inoculation).

We did not find any significant difference in nematode infections between Col-0 grown on MS and Col-0 grown modified KNOPs media (Sijmons et al., 1991) in our set-up (Supplementary Figure 1). Therefore, for all other nematode bioassays using JA biosynthetic mutants, 14 day old seedlings were grown on MS media, $\mathrm{pH}$ 5.7. The seedlings were in individual six well plates and each plant was inoculated with $100 \mathrm{M}$. hapla. The inoculated plants were kept in the dark at $22^{\circ} \mathrm{C}$ as this facilitates infection for root-knot nematode bioassays (Kyndt et al., 2016). Galls per plant were counted at $14 \mathrm{dpi}$. At $14 \mathrm{dpi}$, we observed galling, but the nematodes had not yet laid eggs. All experiments were repeated at least three times. All statistical analyses were performed using JMP software.

To monitor nematode penetration and infections, two week old seedlings were each inoculated with $100 \mathrm{M}$. hapla J2. At 4 dpi the plants were stained with acid fuchsin. These plants were placed into $50 \%$ commercial bleach solution for $2 \mathrm{~min}$, rinsed with $\mathrm{H}_{2} \mathrm{O}$ and then placed into a boiling, 1/30 diluted, acid fuchsin staining solution (35 mg Acid fuchsin/100 mL) for $1 \mathrm{~min}$. The stained plants were rinsed in $\mathrm{H}_{2} \mathrm{O}$ and observed under a stereo-microscope.

\section{Quantitative Reverse-Transcriptase Polymerase Chain Reaction (qRT-PCR)}

Total RNA extraction and quantitative reverse-transcriptase polymerase chain reaction (qRT-PCR) analysis were performed as described (Fode et al., 2008). Calculations were done according to the $2^{-\triangle \mathrm{CT}}$ method (Livak and Schmittgen, 2001). UBQ5 served as a reference (Kesarwani et al., 2007; Zander et al., 2010; Koster et al., 2012; Ralhan et al., 2012). Primers used to amplify and quantify the cDNA are as follows: VSP2 Forward 5' -CAAACTAAACAATAAACCATACCATAA-3', VSP2 Reverse 5'-GCCAAGAGCAAGAGAAGTGA-3'. UBQ5 Forward 5'-GACGCTTCATCTCGTCC-3', UBQ5 Reverse 5'GTAAACGTAGGTGAGTCCA-3'.

\section{coi1-t Genotyping}

Genomic DNA from leaves of infected plants was extracted DNeasy Plant Mini Kit (Quiagen, Valencia, CA, USA). This DNA was used as template for a three-primer polymerase chain reaction (PCR), to genotype the plants and determine which plants carry the T-insertion. A Standard PCR reaction was performed using reagents from the Advantage 2 PCR Enzyme System (Clontech). In the $10 \mu \mathrm{L}$ reaction, the final primer 
concentrations were $0.5 \mu \mathrm{M}$ and a final dNTP concentration was $0.2 \mu \mathrm{M}$. The reaction was conducted for 35 cycles at: $94^{\circ} \mathrm{C}$ 1 min., each cycle $94^{\circ} \mathrm{C}$ for 30 s., $68^{\circ} \mathrm{C}$ for $2: 30 \mathrm{~min}$. The primers used were as follows: COI1 Left Border (COI1 LB) $5^{\prime}$ TGGACCATATAAATTCATGCAGTCAACAAC-3', COI1 Right Border (COI1 RB) 5' -CTGCAGTGTGTAACGATGCTCAAAAG TC-3', and LBb1.3 5'-ATTTTGCCGATTTCGGAAC- $3^{\prime}$. The products were separated on a $2 \%$ agarose gel. Wild-type plants will have a product only from the COI1 RB and COI1 LB primers (Mosblech et al., 2011).

\section{Plant Phytohormone Measurement by HPLC/MS}

Eight day old Col-0 seedlings were transferred from MS media to MS media with or without $50 \mu \mathrm{M}$ MeJA. The samples were collected after 48 hours of treatment and approximately $100 \mathrm{mg}$ of root material (from approximately 500 seedlings) from three biological replicates were used. The extraction was performed as previously described in Matyash et al. (2008) with some modifications. Briefly, $100 \mathrm{mg}$ frozen material was finely milled and extracted with $0.75 \mathrm{~mL}$ methanol and $2.5 \mathrm{~mL}$ MTBE (Methyl-tert-butylether) in the dark for $1 \mathrm{~h}$ at $4^{\circ} \mathrm{C}$ and constant shaking. To allow quantification deuterated standards (10 ng D6-JA, 30 ng D5-oPDA, 10 ng D3-JALeu, and 20 ng D5-IAA) were added to each sample. To enhance phase separation, $0.6 \mathrm{~mL}$ water was added to the sample before centrifugation. The upper phase was collected; the lower phase was re-extracted with $0.7 \mathrm{~mL}$ methanol/water (3:2.5, $\mathrm{v} / \mathrm{v})$ and $1.3 \mathrm{~mL}$ MTBE. Supernatants were combined and evaporated under a nitrogen stream. The residue was solved in $100 \mu \mathrm{L}$ acetonitrile/water/acetic acid (20:80:0.1, v/v/v). During all extraction steps, direct light exposure was avoided to prevent photoisomerization. Further, between all steps samples were overlaid with argon to avoid autooxidation. Samples were subjected for phytohormone measurements on a HPLC-MS/MS as described by Iven et al. (2012).

Mass transitions (in Da) were as follows: 215/59 for D6-JA and 209/59 for JA; 296/170 for D5-oPDA, 263/165 for dinor-oPDA and 291/165 for cis-oPDA; 325/133 for D3-JA-Leu and 322/130 for JA-IleLeu; 179/135 for D5-IAA and 174/130 for IAA.

\section{RESULTS}

\section{Exogenous Application of MeJA and COR Elicits Nematode Resistance in Arabidopsis}

Exogenous application of MeJA has been shown to protect against $M$. incognita and $M$. javanica in several diverse crop plants and against M. graminicola in rice (Soriano et al., 2004a,b; Cooper et al., 2005; Nahar et al., 2011). The northern root-knot nematode M. hapla has a different host range to M. incognita. M. hapla also has a smaller genome and is found in more temperate climates. We wanted to determine if an exogenous application MeJA can induce resistance to $M$. hapla in Arabidopsis, and moreover, see if this induced resistance was specific to MeJA or
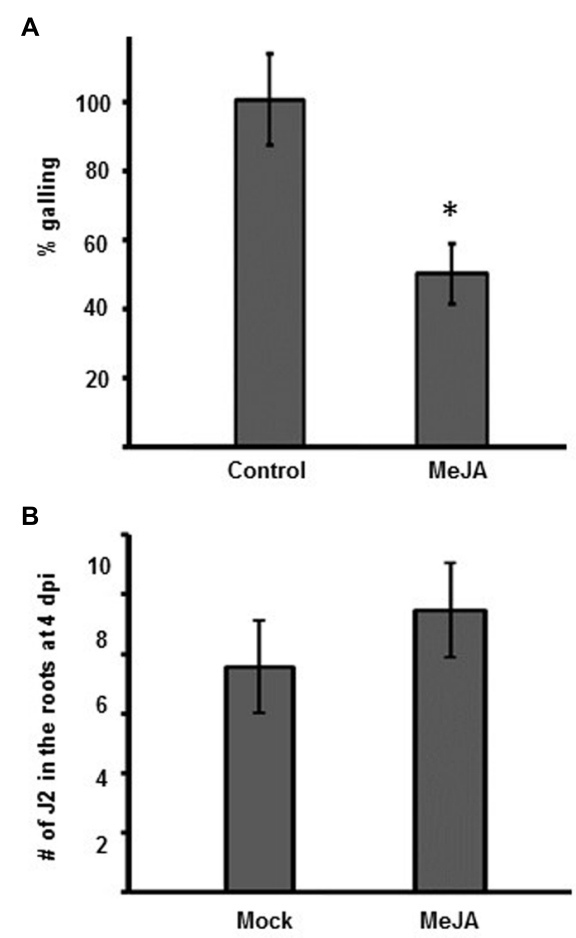

FIGURE 2 | Galling is reduced in Arabidopsis after MeJA. (A) Relative galling at $14 \mathrm{dpi}$ in Col-0 plants with or without pre-treatment with MeJA. The galling in untreated Col-0 (Control) was set to 100\%. Values show the mean \pm SE of three independent experiments. Untreated control $n=235$, MeJA $n=155$. Asterisk indicates a significant different between control and treatment group (Welch $t$-test $* p<0.005$. (B) Number of $\mathrm{J} 2$ in the roots of plants, with or without $50 \mu \mathrm{M}$ MeJA pre-treatment, at $4 \mathrm{dpi}$. Values are the means \pm SE from three independent experiments $(n=15)$. No significant difference could be seen between mock and treatment group. Experiment repeated three times with similar results.

if it could also be induced by the JA-analog COR. Therefore, we performed infection assays on plants pre-treated with MeJA or COR. Eight-day old Col-0 seedlings were transferred to Murashige-Skoog (MS) medium with or without $50 \mu \mathrm{M}$ MeJA or $1 \mu \mathrm{M}$ COR for $48 \mathrm{~h}$. Plants treated with either MeJA or COR for $48 \mathrm{~h}$ showed enhanced expression of the JA-marker gene VSP2 (VEGETATIVE STORAGE PROTEIN2) in both leaves and roots, compared to the untreated plants, indicating that JA-responses had been switched on by the treatments (Supplementary Figures 2 and 3). After $48 \mathrm{~h}$ of treatment, was no significant effect on root length by MeJA or COR; all seedlings were transferred onto media lacking MeJA and COR and subsequently inoculated with 100 M. hapla juveniles. At $14 \mathrm{dpi}$, the number of galls per plant was counted. The results show that exogenous MeJA treatment reduced galling by approximately 50\% (Figure 2B; Supplementary Figure 2). The pre-treatment with COR also significantly reduced galling by $25 \%$ compared to galling in the un-treated plants (Supplementary Figure 3).

MeJA pre-treatment had a stronger effect on galling compared to the COR pre-treatment (Figure 2A; Supplementary Figure 3B). 


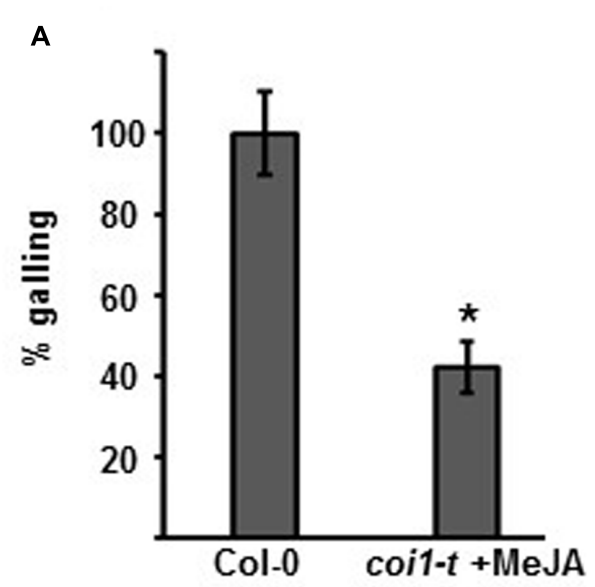

B

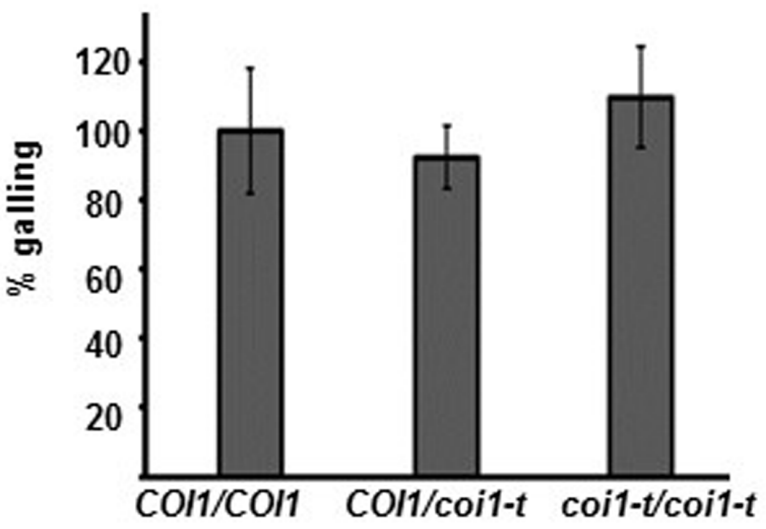

FIGURE 3 | Plant susceptibility to Meloidogyne hapla is

COI1-independent. (A) Col-0 seedlings, grown on MS without selection, and coi1-t seedlings, selected on MS +50 $\mu \mathrm{M}$ MeJA media, were transferred to fresh MS plates and inoculated with $100 \mathrm{M}$. hapla J2 per plant. Galls per plant were counted at $14 \mathrm{dpi}$., and the galling in Col-0 was set to 100\%. Bars represent mean values $( \pm \mathrm{SE})$ from the combined results of three independent experiments (Col-0 $n=149$, coi1-t $n=148)$. Asterisk indicates a significant different between mock and treatment group (Welch $t$-test ${ }^{*} p<0.05$ ).

(B) Ten-day-old seedlings on MS media were inoculated with $100 \mathrm{M}$. hapla J2 per plant. The severity of the infection was determined by counting galls at $14 \mathrm{dpi}$. The genotype of each plant was then determined by PCR (CO/1/CO/1, CO/1/coi1, and coi1/coi1). The average galling in COl1/CO/1 (wild type) was set to $100 \%$. Values represent the means \pm SE from three independent experiments. ( $n=35,75$, and 32 , respectively).

Therefore, we further focused on the effects of MeJA in nematode resistance. To determine whether MeJA treatment of Col-0 had an influence on nematode attraction or root penetration, Col0 seedlings were treated with either water (mock) or MeJA (50 $\mu \mathrm{M}$, final concentration) for $48 \mathrm{~h}$ prior to infection with RKN juveniles. At 4 days post infection, the roots were stained with acid fuchsin to visualize the nematodes that had successfully penetrated the roots. We only observed $\mathrm{J} 2$ in the roots at this time point. There was no significant difference in the number of $\mathrm{J} 2$ in the roots of mock or MeJA treated plants (Figure 2B).

\section{JA Perception is Not Required for Arabidopsis Nematode Susceptibility or the MeJA-Induced Nematode Resistance}

Both the biologically active form of JA (JA-Ile) and COR have affinity for the JA-receptor COI1. We next studied whether Arabidopsis coil-t mutant plants have altered M. hapla susceptibility. Because homozygous coil-t plants are male sterile (Mosblech et al., 2011), the line is maintained with coil$t / C O I 1$ heterozygous plants. To select homozygous coil- $t /$ coil- $t$ plants from the progeny of the coil-t/COI1 heterozygous line, seeds were germinated and grown for 10 days on MS media supplemented with $50 \mu \mathrm{M}$ MeJA. Plants which showed no growth response to MeJA were assumed to be coil-t/coil-t. As a control, Col-0 plants were grown on MS without MeJA. Col-0 and the MeJA-insensitive coil-t/coil- $t$ seedlings were then transferred to MS media. Two week old seedlings were inoculated with 100 $M$. hapla, and the number of galls per plant was counted at $14 \mathrm{dpi}$. The MeJA pre-treated coil-t plants were significantly more resistant than the Col-0 seedlings (Figure 3A, Supplementary Figure 4).

Although coil-t plants are MeJA insensitive, the MeJA preselection for homozygous coil-t plants may have triggered JAdependent, COI1-independent responses, leading to the induced resistance. To circumvent the MeJA pre-treatment, a segregating coil-t/COI1 line was grown on MS medium for 14 days, and the roots were inoculated with $M$. hapla juveniles. The number of galls per plant was counted at 14 dpi. Subsequently, the plants were collected for DNA extraction and the genotype at the COI1 locus was determined by PCR for each plant. The coi1-t/coi1-t plants showed a similar number of galls as the COI1/COI1 and COI1/coil-t plants (Figure 3B; Supplementary Figure 4). This result indicates that COI1 is not significantly involved in the plants' susceptibility to $M$. hapla. The resistance seen in the MeJA-treated plants coil-t plants (Figure 3A) is due to the MeJA pre-treatment and not to the coil-t genotype.

\section{JA Biosynthesis Mutants that Lie Upstream of OPR3 have Enhanced Nematode Susceptibility}

To investigate oxylipin signaling upstream of COI1, we studied the Arabidopsis fatty-acid desaturase triple mutant fad3-2 fad7-2 fad8 that lacks $16: 3(n-3)$ and 18:3(n-3) fatty acids (McConn and Browse, 1996). The fad3-2 fad7-2 fad8 seedlings were inoculated with $M$. hapla juveniles and the number of galls per plant was counted 14 dpi. The fad32 fad7-2 fad8 roots had significantly more galling than the wild-type roots (Figure 4; Supplementary Figure 5). In Arabidopsis the mutant delayed dehiscence2 (dde2-2) is defective in AOS, and as a result, cannot produce JA (von Malek et al., 2002). The dde2-2 plants exhibited enhanced nematode galling compared to the wild type (Figure 4; Supplementary Figure 5).

During the synthesis of oxylipins, AOS acts in a coupled reaction with AOC to produce a JA precursor OPDA. To determine if OPDA has a role in the plant-nematode interaction, 


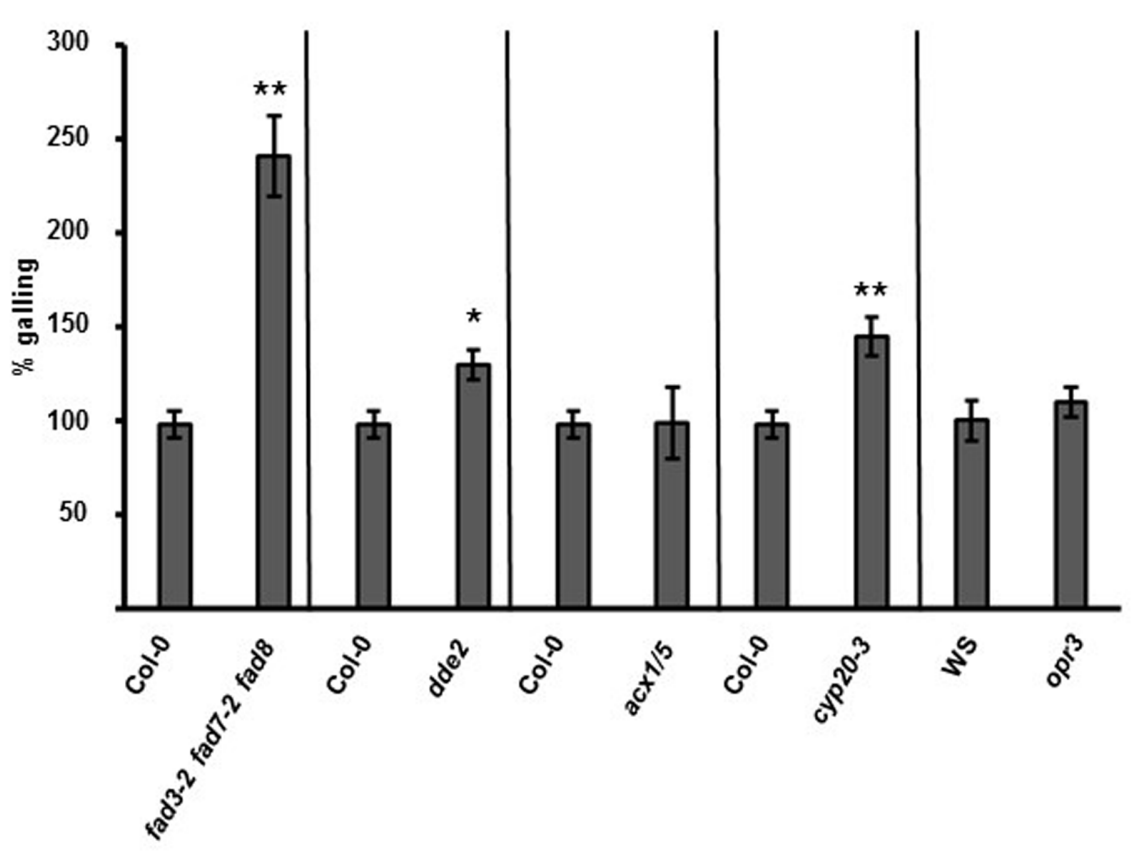

FIGURE 4 | Mutants in the JA biosynthetic pathway show differential susceptibility M. hapla. Fourteen-day-old seedlings on MS media were inoculated with $\mathbf{1 0 0} \mathbf{M}$. hapla $\mathbf{J} \mathbf{2}$ per plant and galls were counted at $\mathbf{1 4} \mathbf{~ d p i . ~ T h e ~ a v e r a g e ~ n u m b e r ~ o f ~ g a l l s ~ i n ~ C o l - 0 ~ a t ~} 14$ dpi was set to $100 \%$ and results are means \pm SE combined from at least three independent experiments. Galling in each mutant was compared to galling in Col-0 (or the Wassilewskija ecotype (WS) for opr3). Asterisk indicates a significant difference between the mutant and control (Welch $t$-test $\left.{ }^{*} p<0.0005,{ }^{* *} p<0.005\right)$. ( $n=117,39,78,47,33,33$, and 29, respectively).

an Arabidopsis mutant opr3, which is compromised in the conversion of OPDA to JA, was tested with nematodes. The opr3 mutant is in the Wassilewskija ecotype (Stintzi and Browse, 2000). The opr3 plants exhibited galling at levels similar to the Wassilewskija control (Figure 4; Supplementary Figure 5).

Next we tested the acx1/5 mutant with M. hapla. The acx1/5 mutant is defective in the $\beta$-oxidation steps downstream of OPR3 in the JA biosynthetic pathway (Schilmiller et al., 2007). At $14 \mathrm{dpi}$, the number of galls were counted in $a c \times 1 / 5$, and the level of galling was to be similar to the Col-0 plants (Figure 4; Supplementary Figure 5).

\section{Plant OPDA Perception is Required to Maintain Wild-Type Levels of Nematode Galling}

Our infection assays have shown that plants that cannot accumulate JA and OPDA are hyper-susceptible to nematodes. However, opr3 plants, which cannot convert OPDA to JA, have wild-type levels of galling. Therefore, OPDA may have a key role in regulating plant susceptibility to nematodes. To test this hypothesis, we measured the $M$. hapla-susceptibility of a mutant in the recently identified OPDA receptor peptidyl-prolyl cis-trans isomerase3 (CYP20-3) (Park et al., 2013). Nematode bioassays were performed on cyp20-3 seedlings, and at $14 \mathrm{dpi}$, there was more galling in the cyp20-3 mutant compared to the wild-type plants (Figure 4; Supplementary Figure 5).

\section{Exogenous MeJA Treatments Increase the Content of JA-Precursors and JA in the Plant}

Since the evidence suggests that OPDA is regulating plant susceptibility to nematodes, we explored whether the MeJAinduced resistance in wild-type plants could be linked to elevated OPDA levels. Exogenous application of MeJA can induce the expression of JA biosynthesis genes (Turner et al., 2002; Wasternack et al., 2006), and this positive feedback loop in JA biosynthesis should result in enhanced OPDA synthesis. However, the effect of exogenous MeJA treatment on Arabidopsis hormone profile had not been fully investigated. Therefore, oxylipin profiling was carried out on roots of eight day old seedlings grown on MS media with or without MeJA treatment. Oxylipin profiling was conducted by using high-performance liquid chromatography/mass spectrometry (RP-HPLC/MS). We found that a $48 \mathrm{hr}-\mathrm{MeJA}$ treatment increased the content of OPDA, dinor-OPDA, JA and JA-IleLeu in the roots compared to the un-treated plants (Figure 5). In addition, the treatment did not affect the amount of auxin in the roots (data not shown).

\section{The Auxin Receptor TIR1 is Required for Nematode Susceptibility}

There is a body of evidence to suggest a positive interplay between oxylipin and auxin (Kazan and Manners, 2008). In addition, the JA receptor (COI1) and the auxin receptor (TIR1, TRANSPORT INHIBITOR RESPONSE 1) are both F box proteins that share 

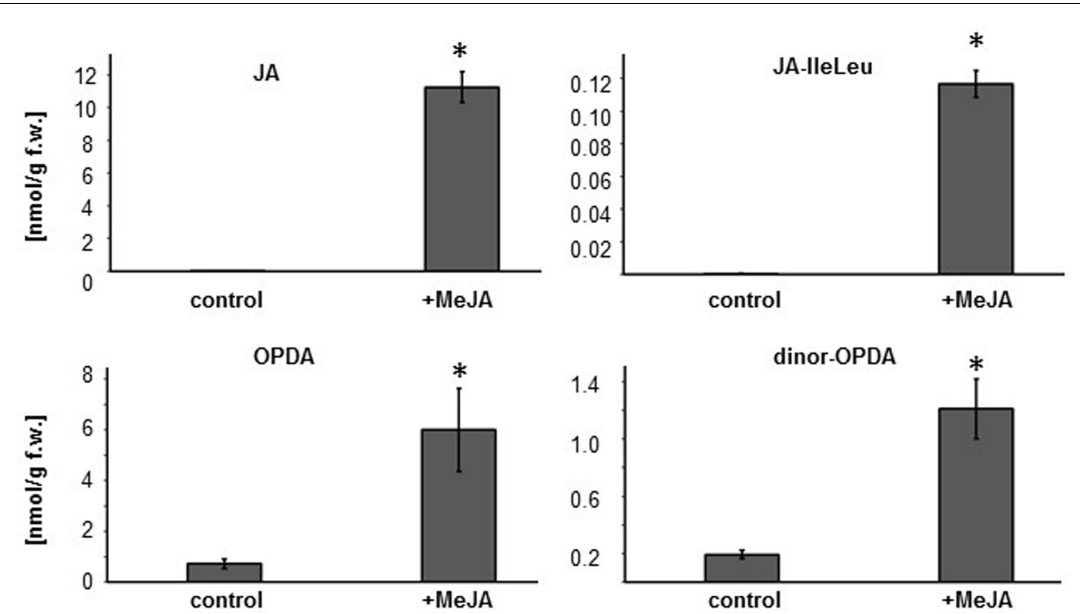

FIGURE 5 | MeJA treatment increases OPDA, dinor-OPDA, JA and JA-IleLeu concentrations in Col-0 roots. Eight day old Col-0 seedlings were transferred onto MS media with or without $50 \mu \mathrm{M}$ MeJA. After $48 \mathrm{~h}$ of treatment, approximately $100 \mathrm{mg}$ of root was used for hormone measurements. Bars represent average $\mathrm{nmol} / \mathrm{gram}$ fresh weight as measured by HPLC/MS. Error bar indicates standard error of mean $(n=3)$. Asterisk indicates a significant different between the mock and MeJA treated roots (student's t-test * $p<0.05$ ).

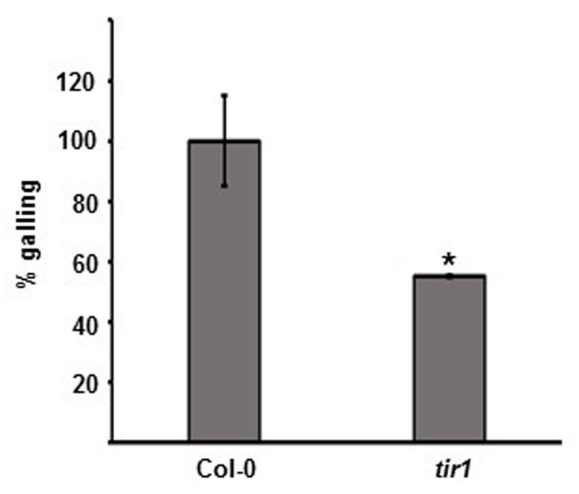

FIGURE 6 | The mutant in auxin perception tir1 is more resistant to M. hapla. Ten-day-old seedlings were inoculated with $100 \mathrm{M}$. hapla J2 per plant. Galls were counted at 14 dpi. Average galling in Col-0 was set to $100 \%$. Values are means \pm SE. Asterisk indicates a significant difference between Col-0 $(n=58)$ and tir $1(n=37)$ galling (Welch $t$-test $\left.{ }^{*} p<0.01\right)$. Experiment repeated three times with similar results.

structural similarity (Katsir et al., 2008). We next tested the requirement of the nuclear auxin receptor TIR1 in the plantroot-knot nematode interaction. After infection with M. hapla, tir1 plants exhibited significantly less galling than the wild type, indicating that TIR1-mediated auxin signaling is important for nematode susceptibility (Figure 6; Supplementary Figure 6).

\section{DISCUSSION}

By using mutants in the JA biosynthetic pathway, we discovered a branch-point between hyper-susceptibility and wild type-levels of nematode disease symptoms. Mutants in enzymes upstream of OPR3 ( $f a d 3-2$ fad7-2 fad8 and dde2-2) were more susceptible to M. hapla, while plants with mutations in OPR3 (opr3), in downstream enzymes $(a c x 1 / 5)$ or in JA perception (coil- $t$ ) had wild-type galling. Based on our results, we postulate that other mutants in the JA biosynthetic pathway which lie upstream of OPR3 would be more susceptible to nematodes. Consistent with our hypothesis, Ozalvo et al. (2014) found that plants with a deficiency in lipoxygenase LOX4, an enzyme that catalyzes one of the first steps in JA biosynthesis, were more susceptible to nematodes than the control (Ozalvo et al., 2014). The rice hebiba mutant, which contains mutations in AOS, showed enhanced susceptibility to rice root-knot nematodes (Nahar et al., 2011), and mutants affected in JA biosynthesis (dde2-2 and lox6) exhibited enhanced Heterodera schachtii female development (Kammerhofer et al., 2015). In conjunction with the mutant data, it was recently shown that blocking JA biosynthesis in rice by applying lipoxygenase (LOX) inhibitors significantly increased plant susceptibility toward root-knot nematodes (Nahar et al., 2011).

Our data show that plants that cannot produce JA or OPDA are more susceptible to nematodes, and this indicates JA and/or OPDA are the key defense molecule(s) in the plant-nematode interaction. Because opr3 lacks the enzyme that reduces OPDA during JA biosynthesis, we could use opr3 to differentiate between JA and OPDA-specific signaling (Sanders et al., 2000; Stintzi and Browse, 2000). The wild-type level of galling in the opr3 mutant showed that in the absence of JA, OPDA is playing a critical role as a defense signal against nematodes. Interestingly, the validity of the Arabidopsis opr3 work was recently called into question in a report by Chehab et al. (2011). The authors found that opr3 plants produced full-length OPR3 transcripts upon Botrytis infection, revealing that opr3 is not a null mutant, but a conditional, JA producing mutant (Chehab et al., 2011). This is in contrast to the previous work of Stintzi and Browse (2000) who had shown there was no induction of $O P R 3$ transcripts after fungal infection in the opr3 mutant. The conflicting results may be due to differences in experimental conditions and/or pathogens 
that were tested (Botrytis vs. A. brassicicola). The nature of the opr3 mutant continues to be investigated, but a separate study has now confirmed that that Arabidopsis opr3 cannot produce OPR3 transcript upon A. brassicicola infection (Park et al., 2013). In addition, just as the opr 3 mutant was not compromised in resistance to a fungal pathogen, the RNAi - OPR3 tomatoes exhibited high levels of resistance to the larvae of the moth Manduca sexta (Bosch et al., 2014). These data support that opr3 is useful mutant to study OPDA as a defense signaling molecule.

The increased susceptibility of the mutant in OPDAperception (cyp20-3) also supports our hypothesis that OPDA has a major role in the plant-nematode interaction. The binding of OPDA to CYP20-3 alters cellular redox homeostasis and causes changes in gene expression during times of stress (Park et al., 2013). The increased galling in cyp20-3 points to the importance of redox homeostasis in controlling the level of nematode susceptibility.

Although previous reports have shown MeJA can make plants more resistant to nematodes, the body of work has primarily focused on $M$. incognita, M. javanica, or M. graminicola. Here we show that exogenous MeJA application can induce resistance to the Northern root knot nematode M. hapla. MeJA likely has no toxic effects on root-knot nematodes since nematodes soaked in a MeJA solution can still infect and proliferate normally in tomato (Cooper et al., 2005). Alterations in ethylene signaling been shown to affect the attractiveness of a root to nematodes (Gao et al., 2008; Fudali et al., 2013). However, the MeJA-induce resistance was not the result of reduced root attraction or nematode penetration since at $4 \mathrm{dpi}$, there was no significant difference in the number of $\mathrm{J} 2$ in the root of control or MeJA treated plants (Figure 2B). Therefore, the reduction of galling after MeJA treatment was not due to changes in root attractiveness to nematodes or the nematode penetration of the roots. Considering the diversity in host-range, reproduction, and geographic distribution amongst species of root-knot nematodes, MeJA treatment elicits broad-spectrum nematode resistance, and downstream signaling pathways could be targets for manipulation in efforts improve plant resistance.

If OPDA is the main player in regulating plant resistance to nematodes, would exogenous MeJA treatment enhance nematode resistance? Our data supports the possibility that MeJA induces OPDA synthesis because the overall root content of OPDA and dn-OPDA increased after exogenous MeJA treatment in Col-0 plants. However, it is important to note that JA and JAIleLeu also accumulated in the plants after the MeJA treatment. Therefore, we cannot completely rule out the contribution of JA/JA-Ile in the induced resistance response, and it is possible that the level of pathogen resistance may be due to the additive or synergistic effects of JA and/or other oxylipins (i.e., OPDA) (Park et al., 2013). Interestingly treating Arabidopsis with exogenous application of hexanoic acid primed the plants for production of OPDA and JA-Ile and increased plant resistance to Botrytis (Kravchuk et al., 2011). It would be interesting to investigate if hexanoic acid could also induce nematode resistance.

Although the effect was not as strong as with MeJA, the exogenous application of COR also reduced gall numbers. Since the JA-conjugate (JA-Ile) and COR can bind to the COI1-complex to activate JA-signaling, we initially thought that COI1 would be necessary for the induced resistance response. Surprisingly, the MeJA-treated COI1 seedlings also exhibited enhanced nematode resistance, indicating that the resistance was JA-dependent but COI1 independent. When we performed nematode bioassays in key JA biosynthetic mutants, OPDA and not JA played a key role in plant defenses against nematode. Based on the induced resistance response and the mutant data, we predict that in the absence of JA, OPDA is key for regulating plant immunity against nematodes. Since a pharmacological approach could not completely rule out the role of JA in the induced resistance response, we predict that the MeJA-induced resistance is likely due to the effects of both JA and OPDA acting through COI1independent gene expression. The importance of JA in the induced response was re-iterated by the MeJA-induced resistance in coilt plants. Future experiments will address if induced resistance can be linked to an overlapping set of genes which are regulated by both JA and OPDA in a COI1-independent manner.

To further clarify the role of COI1 in the plant-nematode interaction, we then tested coil-t plants in a nematode bioassay without the MeJA pre-selection and found that these plants were just as susceptible as wild-type plants. This result is in contrast to that of Bhattarai et al. (2008), who found that in tomato, rootknot nematode susceptibility was dependent on COI1 mediated signaling. The differences in the requirement of COI1 may be the result of the different plant species used (tomato vs. Arabidopsis). In addition, the heterozygous population of the tomato jail mutant had initially been screened for MeJA sensitivity (Bhattarai et al., 2008). A recent report found that MeJA treatment could induce nematode resistance for at least 1 week after the foliar application in tomato plants (Fujimoto et al., 2011), and thus, MeJA treatment may have a long lasting effects on plant responses to nematodes.

Although the focus of this study was on JA and members of the jasmonate family, hormone crosstalk plays an important role in tailoring these responses depending on the type of pathogen or stress encountered (Verhage et al., 2010; Robert-Seilaniantz et al., 2011). The cross talk between JA and auxin is generally positive, but a recent report found that when roots are exposed to high exogenous JA concentrations $(50 \mu \mathrm{M})$, accumulation of the polar auxin transporter PIN2 on the plasma membrane is reduced, and by affecting the abundance of PIN proteins at the plasma membrane, JA may have a repressive role in auxin transport (Kazan and Manners, 2008; Sun et al., 2011). Interestingly, polar auxin transport (PAT) via specific PIN auxin influx carriers is crucial for the initiation and formation of the cyst nematode feeding site (Grunewald et al., 2009). For rootknot nematodes, there is a local accumulation of auxin at the nematode feeding sites and auxin responsive genes are turnedon in the gall tissue (Karczmarek et al., 2004; Grunewald et al., 2008). In addition, a recent report has shown that auxin import into root-knot nematode feeding sites is important for feeding site development and expansion (Kyndt et al., 2016). Perception of a local endogenous auxin accumulation in the cells would require the plant's auxin receptor TIR1, an F-box protein that is part of the SKP1-Cullin-F-box protein complex (SCF ${ }^{\mathrm{TIR} 1}$ ) (Ruegger et al., 1998; Gray et al., 2001). The auxin receptor TIR1 
is homologous to COI1; nevertheless, we found that while COI1 was not needed for nematode susceptibility, TIR1 was required for full nematode susceptibility as the tir1 plants were more resistant to nematodes. Additional work needs to be performed to draw links between JA, OPDA, and auxin signaling in the plant-nematode interaction. However, in a recent paper looking at Sclerotinia sclerotiorum-infected Arabidopsis, there was partial overlap in the defense genes induced by $S$. sclerotiorum and those induced by exogenous OPDA treatment (Stotz et al., 2011). Most of these overlapping genes were expressed in a COI1independent manner, and interestingly, the COI1-independent defenses against $S$. sclerotiorum were regulated by auxin signaling via ARF2 (Auxin Response Factor 2) (Stotz et al., 2011).

\section{AUTHOR CONTRIBUTIONS}

CG and IF designed the study; CG, NL, and DM performed the experiments. CG wrote the manuscript.

\section{REFERENCES}

Bannenberg, G., Martinez, M., Hamberg, M., and Castresana, C. (2009). Diversity of the enzymatic activity in the lipoxygenase gene family of Arabidopsis thaliana. Lipids 44, 85-95. doi: 10.1007/s11745-008-3245-7

Barcala, M., Garcia, A., Cabrera, J., Casson, S., Lindsey, K., Favery, B., et al. (2010). Early transcriptomic events in microdissected Arabidopsis nematode-induced giant cells. Plant J. 61, 698-712. doi: 10.1111/j.1365-313X.2009.04098.x

Bender, C. L., Alarcon-Chaidez, F., and Gross, D. C. (1999). Pseudomonas syringae phytotoxins: mode of action, regulation, and biosynthesis by peptide and polyketide synthetases. Microbiol. Mol. Biol. Rev. 63, 266-292.

Bhattarai, K. K., Xie, Q. G., Mantelin, S., Bishnoi, U., Girke, T., Navarre, D. A., et al. (2008). Tomato susceptibility to root-knot nematodes requires an intact jasmonic acid signaling pathway. Mol. Plant Microbe Interact. 21, 1205-1214. doi: 10.1094/MPMI-21-9-1205

Bosch, M., Wright, L. P., Gershenzon, J., Wasternack, C., Hause, B., Schaller, A., et al. (2014). Jasmonic acid and its precursor 12-oxophytodienoic acid control different aspects of constitutive and induced herbivore defenses in tomato. Plant Physiol. 166, 396-410. doi: 10.1104/pp.114.237388

Brooks, D. M., Bender, C. L., and Kunkel, B. N. (2005). The Pseudomonas syringae phytotoxin coronatine promotes virulence by overcoming salicylic acid-dependent defences in Arabidopsis thaliana. Mol. Plant Pathol. 6, 629-639. doi: 10.1111/j.1364-3703.2005.00311.x

Browse, J. (2005). Jasmonate: an oxylipin signal with many roles in plants. Vitam. Horm. 72, 431-456. doi: 10.1016/S0083-6729(05)72012-4

Chehab, E. W., Kim, S., Savchenko, T., Kliebenstein, D., Dehesh, K., and Braam, J. (2011). Intronic T-DNA insertion renders Arabidopsis opr3 a conditional jasmonic acid-producing mutant. Plant Physiol. 156, 770-778. doi: 10.1104/pp.111.174169

Chini, A., Fonseca, S., Fernandez, G., Adie, B., Chico, J. M., Lorenzo, O., et al. (2007). The JAZ family of repressors is the missing link in jasmonate signalling. Nature 448, 666-671. doi: 10.1038/nature06006

Cooper, W. R., Jia, L., and Goggin, L. (2005). Effects of jasmonate-induced defenses on root-knot nematode infection of resistant and susceptible tomato cultivars. J. Chem. Ecol. 31, 1953-1967. doi: 10.1007/s10886-005-6070-y

Cui, J., Bahrami, A. K., Pringle, E. G., Hernandez-Guzman, G., Bender, C. L., Pierce, N. E., et al. (2005). Pseudomonas syringae manipulates systemic plant defenses against pathogens and herbivores. Proc. Natl. Acad. Sci. U.S.A. 102, 1791-1796. doi: 10.1073/pnas.0409450102

Damiani, I., Baldacci-Cresp, F., Hopkins, J., Andrio, E., Balzergue, S., Lecomte, P., et al. (2012). Plant genes involved in harbouring symbiotic rhizobia or pathogenic nematodes. New Phytol. 194, 511-522. doi: 10.1111/j.14698137.2011.04046.x

\section{FUNDING}

We acknowledge the financial support of the Deutsche Forschungsgemeinshaft (Grant no.GL729/1-1 to CG).

\section{ACKNOWLEDGMENTS}

IF and DM thank Sabine Freitag for technical assistance. CG and NL are grateful to Prof. Dr. Christiane Gatz and coworkers (Georg-August-University Göttingen) for help and support. We thank Hanno Resemann for the JA biosynthesis schematic.

\section{SUPPLEMENTARY MATERIAL}

The Supplementary Material for this article can be found online at: http://journal.frontiersin.org/article/10.3389/fpls.2016.01565

de Almeida Engler, J., and Gheysen, G. (2013). Nematode-induced endoreduplication in plant host cells: why and how? Mol. Plant Microbe Interact. 26, 17-24. doi: 10.1094/MPMI-05-12-0128-CR

Devoto, A., Ellis, C., Magusin, A., Chang, H. S., Chilcott, C., Zhu, T., et al. (2005). Expression profiling reveals COI1 to be a key regulator of genes involved in wound- and methyl jasmonate-induced secondary metabolism, defence, and hormone interactions. Plant Mol. Biol. 58, 497-513. doi: 10.1007/s11103-0057306-5

Dominguez-Solis, J. R., He, Z., Lima, A., Ting, J., Buchanan, B. B., and Luan, S. (2008). A cyclophilin links redox and light signals to cysteine biosynthesis and stress responses in chloroplasts. Proc. Natl. Acad. Sci. U.S.A. 105, 16386-16391. doi: 10.1073/pnas.0808204105

Feys, B., Benedetti, C. E., Penfold, C. N., and Turner, J. G. (1994). Arabidopsis mutants selected for resistance to the phytotoxin coronatine are male sterile, insensitive to methyl jasmonate, and resistant to a bacterial pathogen. Plant Cell 6, 751-759. doi: 10.1105/tpc.6.5.751

Fode, B., Siemsen, T., Thurow, C., Weigel, R., and Gatz, C. (2008). The Arabidopsis GRAS protein SCL14 interacts with class II TGA transcription factors and is essential for the activation of stress-inducible promoters. Plant Cell 20, 3122-3135. doi: 10.1105/tpc.108.058974

Fonseca, S., Chini, A., Hamberg, M., Adie, B., Porzel, A., Kramell, R., et al. (2009). (+)-7-iso-Jasmonoyl-L-isoleucine is the endogenous bioactive jasmonate. Nat. Chem. Biol. 5, 344-350. doi: 10.1038/nchembio.161

Fudali, S. L., Wang, C., and Williamson, V. M. (2013). Ethylene signaling pathway modulates attractiveness of host roots to the root-knot nematode Meloidogyne hapla. Mol. Plant Microbe Interact. 26, 75-86. doi: 10.1094/MPMI-05-120107-R

Fujimoto, T., Tomitaka, Y., Abe, H., Tsuda, S., Futai, K., and Mizukubo, T. (2011). Expression profile of jasmonic acid-induced genes and the induced resistance against the root-knot nematode (Meloidogyne incognita) in tomato plants (Solanum lycopersicum) after foliar treatment with methyl jasmonate. Plant Physiol. 168, 1084-1097. doi: 10.1016/j.jplph.2010. 12.002

Gao, X., Starr, J., Gobel, C., Engelberth, J., Feussner, I., Tumlinson, J., et al. (2008). Maize 9-lipoxygenase $\mathrm{ZmLOX3}$ controls development, root-specific expression of defense genes, and resistance to root-knot nematodes. Mol. Plant Microbe Interact. 21, 98-109. doi: 10.1094/MPMI-21-1-0098

Gheysen, G., and Mitchum, M. G. (2011). How nematodes manipulate plant development pathways for infection. Curr. Opin. Plant Biol. 14, 415-421. doi: 10.1016/j.pbi.2011.03.012

Glazebrook, J. (2005). Contrasting mechanisms of defense against biotrophic and necrotrophic pathogens. Annu. Rev. Phytopathol. 43, 205-227. doi: 10.1146/annurev.phyto.43.040204.135923 
Gleason, C. A., Liu, Q. L., and Williamson, V. M. (2008). Silencing a candidate nematode effector gene corresponding to the tomato resistance gene $\mathrm{Mi}-1$ leads to acquisition of virulence. Mol. Plant Microbe Interact. 21, 576-585. doi: 10.1094/MPMI-21-5-0576

Gray, W. M., Kepinski, S., Rouse, D., Leyser, O., and Estelle, M. (2001). Auxin regulates SCF(TIR1)-dependent degradation of AUX/IAA proteins. Nature 414, 271-276. doi: 10.1038/35104500

Grunewald, W., Cannoot, B., Friml, J., and Gheysen, G. (2009). Parasitic nematodes modulate PIN-mediated auxin transport to facilitate infection. PLoS Pathog 5:e1000266. doi: 10.1371/journal.ppat.1000266

Grunewald, W., Karimi, M., Wieczorek, K., Van de Cappelle, E., Wischnitzki, E., Grundler, F., et al. (2008). A role for AtWRKY23 in feeding site establishment of plant-parasitic nematodes. Plant Physiol. 148, 358-368. doi: 10.1104/pp.108.119131

Heitz, T., Smirnova, E., Widemann, E., Aubert, Y., Pinot, F., and Menard, R. (2016). The rise and fall of jasmonate biological activities. Subcell. Biochem. 86, 405-426. doi: 10.1007/978-3-319-25979-6_16

Ithal, N., Recknor, J., Nettleton, D., Hearne, L., Maier, T., Baum, T. J., et al. (2007a). Parallel genome-wide expression profiling of host and pathogen during soybean cyst nematode infection of soybean. Mol. Plant Microbe Interact. 20, 293-305. doi: 10.1094/MPMI-20-3-0293

Ithal, N., Recknor, J., Nettleton, D., Maier, T., Baum, T. J., and Mitchum, M. G. (2007b). Developmental transcript profiling of cyst nematode feeding cells in soybean roots. Mol. Plant Microbe Interact. 20, 510-525. doi: 10.1094/MPMI20-5- 0510

Iven, T., Konig, S., Singh, S., Braus-Stromeyer, S. A., Bischoff, M., Tietze, L. F., et al. (2012). Transcriptional activation and production of tryptophanderived secondary metabolites in arabidopsis roots contributes to the defense against the fungal vascular pathogen Verticillium longisporum. Mol. Plant 5, 1389-1402. doi: 10.1093/mp/sss044

Kammerhofer, N., Radakovic, Z., Regis, J. M., Dobrev, P., Vankova, R., Grundler, F. M., et al. (2015). Role of stress-related hormones in plant defence during early infection of the cyst nematode Heterodera schachtii in Arabidopsis. New Phytol. 207, 778-789. doi: 10.1111/nph.13395

Karczmarek, A., Overmars, H., Helder, J., and Goverse, A. (2004). Feeding cell development by cyst and root-knot nematodes involves a similar early, local and transient activation of a specific auxin-inducible promoter element. Mol. Plant Pathol. 5, 343-346. doi: 10.1111/j.1364-3703.2004.00230.x

Katsir, L., Schilmiller, A. L., Staswick, P. E., He, S. Y., and Howe, G. A. (2008). COI1 is a critical component of a receptor for jasmonate and the bacterial virulence factor coronatine. Proc. Natl. Acad. Sci. U.S.A. 105, 7100-7105. doi: 10.1073/pnas.0802332105

Kazan, K., and Manners, J. M. (2008). Jasmonate signaling: toward an integrated view. Plant Physiol. 146, 1459-1468. doi: 10.1104/pp.107.115717

Kesarwani, M., Yoo, J., and Dong, X. (2007). Genetic interactions of TGA transcription factors in the regulation of pathogenesis-related genes and disease resistance in Arabidopsis. Plant Physiol. 144, 336-346. doi: 10.1104/pp.106.095299

Koenning, S. R., Overstreet, C., Noling, J. W., Donald, P. A., Becker, J. O., and Fortnum, B. A. (1999). Survey of crop losses in response to phytoparasitic nematodes in the United States for 1994. J. Nematol. 31, 587-618.

Koster, J., Thurow, C., Kruse, K., Meier, A., Iven, T., Feussner, I., et al. (2012). Xenobiotic- and jasmonic acid-inducible signal transduction pathways have become interdependent at the Arabidopsis CYP81D11 promoter. Plant Physiol. 159, 391-402. doi: 10.1104/pp.112.194274

Kravchuk, Z., Vicedo, B., Flors, V., Camanes, G., Gonzalez-Bosch, C., and GarciaAgustin, P. (2011). Priming for JA-dependent defenses using hexanoic acid is an effective mechanism to protect Arabidopsis against B. cinerea. Plant Physiol. 168, 359-366. doi: 10.1016/j.jplph.2010.07.028

Kyndt, T., Goverse, A., Haegeman, A., Warmerdam, S., Wanjau, C., Jahani, M., et al. (2016). Redirection of auxin flow in Arabidopsis thaliana roots after infection by root-knot nematodes. J. Exp. Bot. 67, 4559-4570. doi: 10.1093/jxb/erw230

Livak, K. J., and Schmittgen, T. D. (2001). Analysis of relative gene expression data using real-time quantitative PCR and the 2(-Delta Delta C(T)) method. Methods 25, 402-408. doi: 10.1006/meth.2001.1262

Matyash, V., Liebisch, G., Kurzchalia, T. V., Shevchenko, A., and Schwudke, D. (2008). Lipid extraction by methyl-tert-butyl ether for high-throughput lipidomics. J. Lipid Res. 49, 1137-1146. doi: 10.1194/jlr.D700041-J LR200

McConn, M., and Browse, J. (1996). The critical requirement for linolenic acid is pollen development, not photosynthesis, in an Arabidopsis mutant. Plant Cell 8, 403-416. doi: $10.1105 /$ tpc.8.3.403

Melotto, M., Underwood, W., Koczan, J., Nomura, K., and He, S. Y. (2006). Plant stomata function in innate immunity against bacterial invasion. Cell 126, 969-980. doi: 10.1016/j.cell.2006.06.054

Mosblech, A., Thurow, C., Gatz, C., Feussner, I., and Heilmann, I. (2011). Jasmonic acid perception by COI1 involves inositol polyphosphates in Arabidopsis thaliana. Plant J. 65, 949-957. doi: 10.1111/j.1365-313X.2011.04480.x

Nahar, K., Kyndt, T., De Vleesschauwer, D., Hofte, M., and Gheysen, G. (2011). The jasmonate pathway is a key player in systemically induced defense against root knot nematodes in rice. Plant Physiol. 157, 305-316. doi: 10.1104/pp. 111.177576

Ozalvo, R., Cabrera, J., Escobar, C., Christensen, S. A., Borrego, E. J., Kolomiets, M. V., et al. (2014). Two closely related members of Arabidopsis 13lipoxygenases (13-LOXs), LOX3 and LOX4, reveal distinct functions in response to plant-parasitic nematode infection. Mol. Plant Pathol. 15, 319-332. doi: 10.1111/mpp.12094

Park, S. W., Li, W., Viehhauser, A., He, B., Kim, S., Nilsson, A. K., et al. (2013). Cyclophilin 20-3 relays a 12-oxo-phytodienoic acid signal during stress responsive regulation of cellular redox homeostasis. Proc. Natl. Acad. Sci. U.S.A. 110, 9559-9564. doi: 10.1073/pnas.1218872110

Perry, R. N., and Moens, M. (2013). Plant Nematology. Boston, MA: CABI.

Ralhan, A., Schottle, S., Thurow, C., Iven, T., Feussner, I., Polle, A., et al. (2012). The vascular pathogen Verticillium longisporum requires a jasmonic acidindependent COI1 function in roots to elicit disease symptoms in Arabidopsis shoots. Plant Physiol. 159, 1192-1203. doi: 10.1104/pp.112.198598

Robert-Seilaniantz, A., Grant, M., and Jones, J. D. (2011). Hormone crosstalk in plant disease and defense: more than just jasmonate-salicylate antagonism. Annu. Rev. Phytopathol. 49, 317-343. doi: 10.1146/annurev-phyto-073009114447

Ruegger, M., Dewey, E., Gray, W. M., Hobbie, L., Turner, J., and Estelle, M. (1998). The TIR1 protein of Arabidopsis functions in auxin response and is related to human SKP2 and yeast grr1p. Genes Dev. 12, 198-207. doi: 10.1101/gad.12.2.198

Sanders, P. M., Lee, P. Y., Biesgen, C., Boone, J. D., Beals, T. P., Weiler, E. W., et al. (2000). The arabidopsis DELAYED DEHISCENCE1 gene encodes an enzyme in the jasmonic acid synthesis pathway. Plant Cell 12, 1041-1061. doi: $10.1105 /$ tpc.12.7.1041

Sasser, J. N., and Freckman, D. W. (1987). "A world perspective on nematology: the role of society," in Vistas on Nematology: A Commemoration of the Twenty-fifth Anniversary of the Society of Nematologist, eds J. A. Veech and D. W. Dickson (Hyattsville, MD: Society of Nematologists), 7-14.

Schilmiller, A. L., Koo, A. J., and Howe, G. A. (2007). Functional diversification of acyl-coenzyme A oxidases in jasmonic acid biosynthesis and action. Plant Physiol. 143, 812-824. doi: 10.1104/pp.106.092916

Shah, J. (2009). Plants under attack: systemic signals in defence. Curr. Opin. Plant Biol. 12, 459-464. doi: 10.1016/j.pbi.2009.05.011

Sijmons, P. C., Grundler, F. M. W., Von Mende, N., Burrows, P. R., and Wyss, U. (1991). Arabidopsis thaliana as a new model host for plant parasitic nematodes. Plant J. 1, 245-254. doi: 10.1111/j.1365-313X.1991.00245.x

Soriano, I. R., Asenstorfer, R. E., Schmidt, O., and Riley, I. T. (2004a). Inducible flavone in oats (Avena sativa) is a novel defense against plantparasitic nematodes. Phytopathology 94, 1207-1214. doi: 10.1094/PHYTO. 2004.94.11.1207

Soriano, I. R., Riley, I. T., Potter, M. J., and Bowers, W. S. (2004b). Phytoecdysteroids: a novel defense against plant-parasitic nematodes. J. Chem. Ecol. 30, 1885-1899. doi: 10.1023/B:JOEC.0000045584.56515.11

Stenzel, I., Hause, B., Miersch, O., Kurz, T., Maucher, H., Weichert, H., et al. (2003). Jasmonate biosynthesis and the allene oxide cyclase family of Arabidopsis thaliana. Plant Mol. Biol. 51, 895-911. doi: 10.1023/A:1023049319723

Stintzi, A., and Browse, J. (2000). The Arabidopsis male-sterile mutant, opr3, lacks the 12-oxophytodienoic acid reductase required for jasmonate synthesis. Proc. Natl. Acad. Sci. U.S.A. 97, 10625-10630. doi: 10.1073/pnas.190264497

Stotz, H. U., Jikumaru, Y., Shimada, Y., Sasaki, E., Stingl, N., Mueller, M. J., et al. (2011). Jasmonate-dependent and COI1-independent defense responses against Sclerotinia sclerotiorum in Arabidopsis thaliana: auxin is part of 
COI1-independent defense signaling. Plant Cell Physiol. 52, 1941-1956. doi: $10.1093 /$ pcp/pcr127

Sun, J., Chen, Q., Qi, L., Jiang, H., Li, S., Xu, Y., et al. (2011). Jasmonate modulates endocytosis and plasma membrane accumulation of the Arabidopsis PIN2 protein. New Phytol. 191, 360-375. doi: 10.1111/j.1469-8137.2011.03713.x

Taki, N., Sasaki-Sekimoto, Y., Obayashi, T., Kikuta, A., Kobayashi, K., Ainai, T., et al. (2005). 12-oxo-phytodienoic acid triggers expression of a distinct set of genes and plays a role in wound-induced gene expression in Arabidopsis. Plant Physiol. 139, 1268-1283. doi: 10.1104/pp.105.067058

Thines, B., Katsir, L., Melotto, M., Niu, Y., Mandaokar, A., Liu, G., et al. (2007). JAZ repressor proteins are targets of the $\mathrm{SCF}(\mathrm{COI} 1)$ complex during jasmonate signalling. Nature 448, 661-665. doi: 10.1038/nature05960

Trudgill, D. L., and Blok, V. C. (2001). Apomictic, polyphagous root-knot nematodes: exceptionally successful and damaging biotrophic root pathogens. Annu. Rev. Phytopathol. 39, 53-77. doi: 10.1146/annurev.phyto.39.1.53

Turner, J. G., Ellis, C., and Devoto, A. (2002). The jasmonate signal pathway. Plant Cell 14(Suppl.), S153-S164.

Verhage, A., van Wees, S. C., and Pieterse, C. M. (2010). Plant immunity: it's the hormones talking, but what do they say? Plant Physiol. 154, 536-540. doi: $10.1104 /$ pp. 110.161570

von Malek, B., van der Graaff, E., Schneitz, K., and Keller, B. (2002). The Arabidopsis male-sterile mutant dde2-2 is defective in the ALLENE OXIDE SYNTHASE gene encoding one of the key enzymes of the jasmonic acid biosynthesis pathway. Planta 216, 187-192. doi: 10.1007/s00425-002-0906-2

Wasternack, C., and Hause, B. (2013). Jasmonates: biosynthesis, perception, signal transduction and action in plant stress response, growth and development. An update to the 2007 review in Annals of Botany. Ann Bot 111, 1021-1058. doi: $10.1093 / \mathrm{aob} / \mathrm{mct} 067$
Wasternack, C., Stenzel, I., Hause, B., Hause, G., Kutter, C., Maucher, H., et al. (2006). The wound response in tomato-role of jasmonic acid. Plant Physiol. 163, 297-306. doi: 10.1016/j.jplph.2005.10.014

Williamson, V. M., and Gleason, C. A. (2003). Plant-nematode interactions. Curr. Opin. Plant Biol. 6, 327-333. doi: 10.1016/S1369-5266(03) 00059-1

Yan, J., Zhang, C., Gu, M., Bai, Z., Zhang, W., Qi, T., et al. (2009). The Arabidopsis CORONATINE INSENSITIVE1 protein is a jasmonate receptor. Plant Cell 21, 2220-2236. doi: 10.1105/tpc. 109.065730

Yan, Y., Stolz, S., Chetelat, A., Reymond, P., Pagni, M., Dubugnon, L., et al. (2007). A downstream mediator in the growth repression limb of the jasmonate pathway. Plant Cell 19, 2470-2483. doi: 10.1105/tpc.107.050708

Zander, M., La Camera, S., Lamotte, O., Metraux, J. P., and Gatz, C. (2010). Arabidopsis thaliana class-II TGA transcription factors are essential activators of jasmonic acid/ethylene-induced defense responses. Plant J. 61, 200-210. doi: 10.1111/j.1365-313X.2009.04044.x

Conflict of Interest Statement: The authors declare that the research was conducted in the absence of any commercial or financial relationships that could be construed as a potential conflict of interest.

Copyright (0) 2016 Gleason, Leelarasamee, Meldau and Feussner. This is an openaccess article distributed under the terms of the Creative Commons Attribution License (CC BY). The use, distribution or reproduction in other forums is permitted, provided the original author(s) or licensor are credited and that the original publication in this journal is cited, in accordance with accepted academic practice. No use, distribution or reproduction is permitted which does not comply with these terms. 